
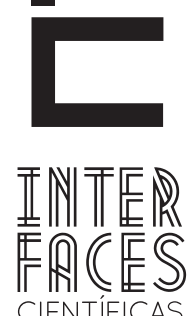

HUMANASE SOCIAIS

ISSN IMPRESSO 2316-3348

E-ISSN 2316-3801

DOI - 10.17564/2316-3801.2018v7n2p31-42

\title{
ENTRE A ASCENSÃO CONSERVADORA E A RESISTÊNCIA FEMINISTA: A PROBLEMÁTICA DO ABORTO NO BRASIL ATUAL
}

BETWEEN THE CONSERVATIVE ASCENDANCY AND THE FEMINIST RESISTANCE: THE ISSUE OF ABORTION IN TODAY'S BRAZIL

ENTRE LA ASCENSIÓN CONSERVADORA Y LA RESISTÉNCIA FEMINISTA: LA PROBLÉMATICA ACTUAL DEL ABORTOEN BRASIL.

\section{RESUMO}

O presente artigo trata-se de uma pesquisa teórica sobre a problemática do abortamento no marco das reivindicações feministas e das medidas desenvolvidas pelo Estado a seu respeito. Diante de valores como intolerância religiosa e recrudescimento do conservadorismo no Brasil, apontamos uma tendência à deslegitimação das poucas ações que visam reconhecer direitos das mulheres nas esferas sexual e reprodutiva, frente ao quadro de regressão de direitos, apontando a relevância social do movimento feminista e as estratégias atuais de manutenção do aborto na sua agenda. Para tal análise, o direcionamento teórico-metodológico utilizado foi o materialismo histórico-dialético, assentando a problemática travada inserida em uma totalidade concreta que cerca as relações sociais na sociedade de classe.

\section{PALAVRAS-CHAVE}

Aborto. Fundamentalismo Religioso. Conservadorismo. Estado. Resistência Feminista. 


\section{ABSTRACT}

This paper is a theoretical research that addresses the issue of abortion in the context of the demands of the feminist movements and of the governmental measures in this regard. In the face of values such as religious intolerance and the ever-increasing conservatism in Brazil, this study points to the trend towards the delegitimization of the already scarce measures in place to assure women's rights in the sexual and reproductive spheres, with regards to the curtailment of fundamental rights, pointing to the social relevance of the feminist movement and to the current strategies to maintain the theme of abor-

\section{RESUMEN}

El presente artículo se refiere al desarrollo de una investigación teórica sobre la problemática de la interrupción del embarazo, enmarcada por las reivindicaciones feministas, así como las medidas desarrolladas por el Estado a su respecto. Frente a distintos factores: como; la intolerancia religiosa y el recrudecimiento del conservadurismo en Brasil, se pone de manifiesto, la deslegitimación de las efímeras acciones que tienen como objetivo reconocer los derechos de las mujeres en los ámbitos sexual y reproductivo. Sin embargo, debido al escenario de regresión de los derechos, señalamos la relevancia social del movimiento feminista y tion in the movement's agenda. In order to reach that aim, the theoretical and methodologicalapproach used in the paper was the one concerning to the historical and dialectical materialism, placing the issue in a material wholeness that surrounds the social relationships in class society.

\section{KEYWORDS}

Abortion. Religious Fundamentalism. Conservatism. Government. Feminist Resistance.

sus estrategias en sus agendas actuales de la manutención del aborto. Para tal análisis, el direccionamiento teórico-metodológico utilizado fue el materialismo histórico-dialéctico, asentando la problemática trabada insertada en una totalidad concreta que rodea las relaciones sociales en la sociedad de clase.

\section{PALABRAS CLAVE}

Aborto. Fundamentalismo Religioso. Conservadurismo. Estado. Resistencia Feminista. 


\section{INTRODUÇãO}

O debato sobre o aborto no Brasil ainda se constitui enquanto tabu e polêmica, em que se dividem opiniões e proporciona o silêncio às mulheres que recorrem ao procedimento na ilegalidade.

0 aborto no Brasil, em sua legislação contemporânea, prevê, no Código Penal, nos art. 124 e 126 a prisão de 1 (um) a 3 (três) anos à mulher que interromper o processo gestacional, seja por realizar o procedimento de abortamento em si ou por consentimento à terceiros. Salvo em duas exceções legislativas e uma por jurisprudênca o aborto no Brasil é legalizado e discriminalizado: no caso de gestação oriundo de estupro; de risco à vida da vida da mulher em processo gestacional; e de fetos anencefálos (BRASIL, 1940; 2004). Entretanto, embora o aborto, fora as exceções já mencionadas, seja proibido no país, as mulheres ainda recorrem a sua prática de forma clandestina a fim de interromper um processo gestacional, em sua grande maioria, indesejado.

A questão sobre 0 abortamento, sendo perpassada por vários elementos e instituições presentes na sociedade e que constituem a superestrutura do sistema capitalista, será analisada a partir da relação do Estado, religião (na sua corrente fundamentalista religiosa) e no conservadorismo por corresponderem a consciência da classe dominante na sociedade de classe qual impede a legalidade e despenalização do aborto no Brasil.

Assim, este trabalho tem como direcionamento a apreensão da realidade concreta que cerca o estudo proposto, a fim de ultrapassar a compreensão imediatista que a aparência proporciona. Portanto, tendo como orientação teórico-metodológico o materialismo histórico-dialético, analisamos a questão do abortamento sua ilegalidade e criminalização - articulado ao projeto de viés misógino da classe dirigente do Brasil.

A situação de abortamento na realidade brasileira atual aponta para fortalecimento de perspectivas e propostas criminalizantes para as mulheres que decidem interromper a gravidez. Esse cenário eviden- cia tensões e contradições frente às reivindicações realizadas pelo movimento feminista, no sentido de a garantia da autonomia das mulheres decidirem sobre seu corpo, de garantia de uma saúde pública e de qualidade para elas e de um novo lugar social enquanto sujeitos históricos.

No limiar desses tensionamentos, o Estado brasileiro, como representante da classe dominante, mas no atual caráter democrático que se apresenta, tem sido tensionado pela correlação de forças entre esferas conservadoras e lutas populares, evidenciando na atualidade profunda articulação com perspectivas religiosas que negam seu caráter constitucionalmente laico.

Desse modo, assentamos neste artigo o debate acerca das configurações do fundamentalismo religioso com caráter conservador e de intolerância quanto aos direitos alcançados pelas mulheres e que tenta refrear avanços e reverter conquistas nesse sentido. Em contraposição a este projeto misógeno, apresentaremos as bandeiras de lutas, sujeitos políticos do feminismo, expressões das conquistas mais recentes e os desafios para a luta feminista classista.

\section{FUNDAMENTALISMO RELIGIOSO E OS ATAQUES AOS DIREITOS DAS MULHERES: EXPRESSÃO DO AVANÇO CONSERVADOR NO BRASIL}

A política sendo uma modalidade da práxis, como Lukács (2013 apud MARTINS, 2015) afirma, se enquadra na superestrutura3 do capitalismo na qual tem seu direcionamento na reprodução social, compondo um campo de disputa de poder a fim de materializar projeto de classe.

A denominação de partidos de direita e esquerda, na arena política, tem sua protoformas na Revolução

3 Consideramos que o sistema capitalista é constituído por duas esferas: a infraestrutura (são os meios, modos e relações de produção, configurando como base material da sociedade, e onde permeiam as relações de exploração da força de trabalho dentro da dinâmica de acumulação de riquezas) e a superestrutura que tem como direcionamento a reprodução da lógica do capitalismo, administrando as relações sociais por meio da estrutura político-jurídico e da ideologia (ENGELS; MARX, 2009). 
Francesa na Assembleia Nacional Constituinte - Assembleia dos Estados Gerais no último quartel do século XVlll em que designa as posições ideo-políticas dos delegados participantes desta Assembleia que objetivava a criação de uma nova Constituição: sentados à direita do rei encontrava-se os delegados identificados com a estrutura aristocrata e com o conservadorismo; à esquerda sentavam-se os que defendiam o igualitarismo e a reforma social. Esta distinção, no decorrer do século XIX na Europa passou a ser relacionado ao conservadorismo e ao liberalismo (TAROUCO; MADEIRA, 2013).

Entretanto, com a expansão de novas forças sociais que nasce da classe trabalhadora, afirmando-se enquanto sujeitos políticos e a difusão da teoria marxista relocam a posição da esquerda, os liberais formam alianças com os conservadores, passando a serem considerados do espectro ideológico da direita e a posição de esquerda, contra o poder estabelecido, centra as pautas revolucionária dos proletariados (TAROUCO; MADEIRA, 2013; SILVA et al., 2014).

$\mathrm{Na}$ contemporaneidade, a esquerda é pautada pela luta em defesa da igualdade, liberdade e justiça social seja pela perspectiva reformista ou revolucionária. Em contrapartida, o espectro ideo-político da direita (instituições, partidos, grupos representantes dos interesses das classes dominantes) configura-se como força política que representa os objetivos do capitalismo: defesa do status quo, dominação, exploração, alienação, monopolização, a propriedade privada, extração de mais-valia e intolerância aos direitos sociais resultantes de processos históricos de lutas das classes trabalhadoras. Além disto, encontramos nos grupos “direitistas” discursos nazifascistas.

Cabee ressaltar que:

A consolidação da hegemonia burguesa, seus mecanismos de reprodução da ordem do capital, a alienação política e os dilemas estratégicos para responder às configurações históricas das necessidades postas pela luta de classes ampliaram o espaço político no qual esquerda e direita se moveram. A experiência do nazifascismo, a geopolítica mundial durante e no imediato pós-Segunda Guerra Mundial, a experiência do Estado de Bem-estar social, a disputa entre os blocos capitalista e socialista são determinações que incidem sobre os campos ideológicos da esquerda e da direita de forma diferenciada em cada sociedade. (SILVA et al., 2014, p. 411).

Essa flexibilidade dificulta as análises no que tange à delineação ideológica das formações políticas em que, de acordo com a formação sócio-histórica do país, tem-se a complexibilização na compreensão da arena política.

Compreende-se que a expressão de intolerância e ódio à democracia é um projeto de base material em que os grupos dominantes que detêm o controle das relações de produção e do poder social repudiam os direitos sociais, o povo (pobre e negro) e os que lutam por uma sociedade justa e igualitária, nos campos políticos, seus representantes estão localizados no governo brasileiro nos partidos denominados de direita.

O bloco da direita, ocupando, portanto, o Congresso Nacional, majoritariamente, são os que desenvolvem projetos de leis, estatutos e de emendas de perfil conservador fundamentado na tradição cristã que impede o avanço da materialização e da discussão dos direitos sexuais e reprodutivos.

Fruto desse embargo, o PL n 5069/2013, que altera o código penal, criminalizando meios de realização do aborto e pessoas que auxiliam mulheres a abortarem; o PL n0 7443/2006, que propõe tipificar o aborto como crime hediondo no código penal, o Estatuto do Nascituro (PL n 478/2007), a Proposta de Emenda Constitucional $n^{0} 164 / 2012$, que altera o conceito de vida na constituição, vinculando-o à concepção, o PL n 1545/2011, altera o código penal colocando como crime o aborto realizado por médico e o $\mathrm{PL} \mathrm{n}^{\circ}$ $5.617 / 2016$, que visa instituir o dia nacional de conscientização antiaborto.

Estas proposições, que têm como fundamento a teologia, se propõem a nivelar o direito à vida tanto da mulher quanto à do feto (concebendo a vida apenas do aspecto da sobrevivência biológica), desprezando as particularidades desta em uma gestação indesejável e a própria história que as mulheres constroem na sua subjetividade. 
Desse modo, afirmamos que as religiões não se estruturam no patamar de neutralidade, pois são mecanismos de legitimação, justificação e imposição de projetos societários e/ou de normas e condutas sociais, cujas atitudes de tolerância em relação à diversidade de crenças foram sempre débeis na sociedade, como a articulação do Estado e Igreja Católica.

A Igreja Católica é a principal instituição na América Latina que lidera a contramobilização aos avanços dos direitos sexuais e reprodutivos desde instauração de governos democráticos. Recentemente, as igrejas protestantes também vêm fazendo parte da ofensiva às pautas sobre reprodução e sexualidade.

A Igreja Católica, como instituição que mais tem poder nos países da América Latina, com foco no Brasil, consegue o apoio de algumas Organizações Não Governamentais (ONG), de setores da sociedade civil, além de representantes que ocupam cargos no Congresso Nacional.

O Estado constitui um instrumento importante para a doutrina cristã assentar suas normas e valores, tendo essa relação sido fundamentada no Brasil Colônia e se estende oficialmente até o Brasil Império ${ }^{4}(1500$ 1889). A estreita relação é decorrência da herança dos colonizadores (invasores) do país, com base na relação que a Coroa portuguesa mantinha com a Igreja Católica. Assim, o catolicismo romano foi considerado a religião oficial do Estado brasileiro até a ascensão do Estado republicano em que instituiu na Constituição Federal de 1891 a separação da Igreja e do Estado, promulgando a laicidade a este último estabelecida constitucionalmente em 1891 (NAME, 2008).

A laicidade estatal é mantida ainda na CF/88 no art. 19, inciso I na qual proíbe as esferas de poder estabelecer cultos religiosos ou igrejas, subvencioná-los, embaraçar-lhes o funcionamento ou manter com eles, ou seus representantes, relações de dependência ou aliança, ressalvada, na forma da lei, a colaboração de interesse público [...] (BRASIL, 1988).

4 No período do Império embora o catolicismo manteve como religião oficial do país, outras religiões e doutrinas foram permitas serem professadas no território brasileiro devido a Constituição instaurada em 1824 que afirma o princípio da liberdade religiosa.
O esforço das instituições religiosas aqui destacado afirma defender a vida para que o aborto continue nas sombras da sociedade mesmo que mulheres morram ou fiquem com sequelas físicas e psíquicas devido a clandestinidade do processo de abortamento, tem seu fundamento na defesa do papel da mulher na sociedade (reprodutora, mãe e submissa), ou seja, é articulado com o patriarcado para controlar não só o corpo feminino mas também as suas decisões, tirando o seu poder de consciência e de autonomia, sendo essa concepção do papel da mulher reforçada pela passagem bíblica em Efésio 5, 22-28:

\begin{abstract}
Vós, mulheres, sujeitai-vos a vossos maridos, como ao Senhor; Porque o marido é a cabeça da mulher, como também Cristo é a cabeça da Igreja, sendo ele próprio o salvador do corpo. De sorte que, assim como a igreja está sujeita a Cristo, assim também as mulheres sejam em tudo sujeitas a seus maridos. Vós, maridos, amai vossas mulheres, como também Cristo amou a Igreja, e a si mesmo se entregou por ela, para a santificar, purificando-a com a lavagem da água, pela palavra, para a apresentar a si mesmo igreja gloriosa, sem mácula, nem ruga, nem coisa semelhante, mas santa e irrepreensível. Assim devem os maridos amar as suas próprias mulheres como a seus próprios corpos. Quem ama a sua mulher, ama-se a si mesmo. (BÍBLIA, 2011, p. 1383).
\end{abstract}

Além da disparidade hierárquica entre mulheres e homens, a Igreja Católica, atualmente pelo Movimento da Renovação Carismática, fortalece o papel da mulher pelo apelo à Nossa Senhora, à Virgem Maria, como imagem de mulher modelo, "concebida sem pecado", tem por objetivo de coordenar e organizar as ações das mulheres e acentuar uma imagem criminalizante do aborto.

Aliado ao uso de texto constitucionais e sendo base de toda retórica cristã para defender a proibição do aborto, o cristianismo utiliza-se de passagens bíblicas para fundamentar o seu posicionamento perante a problemática, conforme Aguierre (2006, p. 13) afirma:

A premissa elementar de todo fiel cristão, como uma constante em toda a revelação bíblica, está no mandamento Não matarás (Ex 20.13). A vida é de Deus e ninguém pode suprimi-la. Em ti está a fonte da vida (SI 35,10). O Gênesis vai acentuar esse mandamento 
dizendo que a vida humana que têm e que eles geram os seres humanos saiu das mãos de Deus como sua obra prima: Tuas mãos me fizeram e me plasmaram... Depois me agraciaste com a vida e tua solicitude conservou a minha respiração (Jó 10,11). Por isso, não é próprio do ser humano a posse radical de sua vida; ele a recebeu de Deus em usufruto. Ele goza dela e a dá, mas imerso no meio divino. 0 ser humano é feito à imagem e semelhança de Deus, seu criador. Esse é seu primeiro título de grandeza e a raiz de todos os outros.

Desse modo, embora a proposição da concepção religiosa contra aborto se deleite nos textos bíblicos, os fundamentalistas religiosos exigem do aparelho estatal e dos seus representantes medidas para assegurar os direitos e a proteção do Estado.

Nos discursos e campanhas das correntes fundamentalistas a defesa da vida é seletiva ${ }^{5}$. Centra-se na defesa da vida de um ser de potencial futuro (embrião) prescindindo muitas vezes da ética e da linha da opinião para discurso de ódio desprezam a realidade social que os cercam: a necessidade urgente de salvar as vidas das mulheres, principalmente as das pobres e negras que em sua grande maioria são suas fiéis $^{6}$, e que morrem em decorrência de um aborto clandestino e inseguro.

Portanto, é pela extrema-direita brasileira que se constituem como a bancada religiosa no Congresso Nacional na qual pautam a defesa à vida e à família natural que o projeto de barrar os avanços constitucionais se materializa, principalmente as pautas de direitos sexuais e reprodutivos. Assim, o Estado incorpora as pautas conservadoras, religiosas e patriarcais baseadas em preceitos não laicos e democráticos para discutir a questão do abortamento, inviabilizando o direito à autonomia e liberdade das mulheres.

Esse ataque aos direitos das mulheres constituem um contraponto organizado à luta dos movimentos feministas que começam a ganhar força na transição dos governos ditatoriais aos democráticos em um movimento que garante visibilidade social às pautas das mulheres, bem como sua inserção na agenda política

5 Como por exemplo, a Campanha da Fraternidade de 2008 com 0 tema "Escolhe, pois, a vida".

6 Assim como mostrada a pesquisa de Diniz e Medeiros (2010). e obtenção de espaços nos aparatos judiciais, impedindo que os fundamentos religiosos recaíssem sobre os textos das Constituições.

\section{A PROBLEMÁTICA DO ABORTO NA AGENDA FE- MINISTA: RESISTÊNCIA ANTICAPITALISTA, ANTI- PATRIARCAL E ANTIFUNDAMENTALISTA}

A consciência dos seres sociais, sendo pela expansão e potencialização da produção e do intercâmbio material que os sujeitos genéricos modificam a si mesmo e a realidade, e proporcionam o desenvolvimento do sentido espiritual consciência humana para a totalidade que os cercam, é definida pelas relações materiais fundantes da sociedade (ENGELS; MARX, 2009).

Portanto, os que detêm o controle dos meios de produção instituem a sua consciência como hegemônica. Esta consciência, regida pela a lógica do sistema capitalista, promove a alienação, a naturalização do capitalismo e dos seus desdobramentos, a reificação dos seres genéricos e a desvinculação do conhecimento e dos fatos sociais.

Desse modo, a consciência social das mulheres e dos homens na sociedade parte da realidade concreta, formando a compreensão generalizada do mundo a partir da experiência individual e subjetiva dos seres sociais dentro da sua condição enquanto classe levando à [...] ações imediatas, desarticuladas e pontuais (ações nas quais os sujeitos ocupam-se, sem transformar a fonte ou fundamentos das realidades) 7 (MONTAÑO; DURIGUETTO, 2011, p. 101; Grifos dos autores).

Cabe aqui ressaltar ao que Marx (2008 apud CISNE, 2014, p. 35) nos atenta: Os homens [e mulheres] fazem a sua própria história, mas não a fazem segundo sua livre vontade, em circunstância escolhidas

7 Atentamos para o fato que essas ações fragmentadas podem apresentar outros determinantes que não seja apenas a consciência em si, como exemplo, a miséria da razão e alienação. 
por eles próprios, mas nas circunstâncias imediatamente encontradas, dadas e transmitidas pelo o passado. Assim, os seres genéricos não são pacíficos diante da realidade que lhe é condicionada: como Cisne (2014, p. 46) aponta,

[...] a consciência é um processo. Por isso, essas características da sua primeira forma de expressão podem ser superadas parcialmente ou em sua totalidade a depender das relações que o indivíduo venha a estabelecer e da forma como as apreende, vivência e interioriza.

É importante ter clareza que sendo a consciência um processo, o sentido dos seres explorados enquanto classe se constitui na transitoriedade da elevação de suas consciências na qualidade de sujeitos coletivos e históricos (CISNE, 2014) com um único inimigo: o capitalismo. Logo, cabe a essa classe desmistificar as multifacetadas desse sistema, estimular a expansão por meio de intervenção política da consciência das massas em direção da luta universal (luta revolucionária) e destruir a naturalização e hegemonia do capitalismo.

Embora as lutas sociais e revolucionária se formem em etapas distintas do processo de tomada de consciência, ambas são dialéticas e interdependentes: a luta de classe necessita do grau de desenvolvimento da luta social para poder ter seu caráter revolucionário. Dessa maneira, as lutas sociais, que aderem o perfil de pontuais e desarticuladas, na realidade consistem como em expressão de um mesmo fenômeno, ou seja, a luta pela igualdade de gênero, sexual, racial, a defesa dos direitos humanos, por exemplo, são lutas que compõe a luta de classe. Nessa direção, Cisne (2014, p. 119) afirma que essas são

Lutas que não podem esperar a grande revolução para resolver problemas pontuais, mas cujos objetivos de curto prazo (como a igualdade de gênero e a questão do aborto, por exemplo) não necessariamente são antagônicos à finalidade de longos prazos (a superação da ordem burguesa).

Embora o sentido mais amplo da luta de classe seja a destruição da centralidade do sistema capitalista, temos que ter o direcionamento que para além da contradição fundante desse modelo organizacional (contradição capital e trabalho), outras formas de contradição emerge neste, como a questão da desigualdade de gênero.

Desse modo, a classe explorada não sendo constituída por sujeitos genéricos homogêneos, e, sim, por seres que, embora estejam sob os mesmos caráteres de exploração, apresentam suas particularidades, como a condição da mulher na sociedade de classe, a luta feminista - que no primeiro momento poderia constituir-se como apenas luta social se associa diretamente na luta pela emancipação humana.

As mulheres sempre lutaram contra as condições postas socialmente seja com maior ou menor organização. Estas sempre estiveram quebrando barreiras no decorrer do movimento histórico, temos como por exemplo: Na Grécia antiga, Safo; no século XIV, Christe de Pisan (1364 1430) em seus discursos pela igualdade entre homens e mulheres; as mulheres (bruxas) queimadas pelo Tribunal da Inquisição; as sufragistas; as líderes operárias Jeanne Deroin (1805-1894) e Flora Tristan (1803 1844); as operarias do 8 de Março"; Simone de Beauvoir (1908 - 1986) pela sua obra que revela a base da desigualdade entre os gêneros; Movimento Feminino pela Anistia; Católicas pelo Direito de Decidir (CDD); Marcha Mundial das Mulheres (MMM); Movimento de Mulheres Camponesas (MMC).

A questão do aborto como bandeira de luta dos movimentos feministas no Brasil e nos países da América Latina começa a ganhar destaque no processo de decaída do regime militar e com a redemocratização que culminou com a maior organização e força do movimento (1970) e, em contrapartida, com avanço do conservadorismo religioso.

Embora a pauta sobre os direitos sexuais e reprodutivos se configure como uma das lutas de maior referência do movimento feminista atualmente, com maior ou menor intensidade a depender das tensões da realidade, foi só em 1970 que, no Brasil, a organização pôs maior pressão no Estado para retirar os artigos do Código Penal de 1940 que criminaliza e torna ilegal a prática de aborto e legalizar e descriminalizar o processo de abortamento. Segundo Biroli (2014), 
o debate no interior do movimento feminista sobre o processo de interrupção voluntária da gestação circunscreve em dois pontos: 1) o debate crítico entre esfera individual e social do processo de abortamento e 2) a defesa da liberdade sexual como via de atingir a legalização e descriminalização do aborto.

Portanto, soma-se à luta reivindicatória a tática de inserção dos sujeitos políticos feministas em partidos políticos e sindicatos no intuito de [...] interferir nos espaços de decisão e de poder através de mecanismos institucionalizado de participação (MAYORGA; MAGALHÃES, 2008, p. 157).

De acordo com Mayorga e Magalhães (2008, p. 158)

\begin{abstract}
Apesar da luta das mulheres na Constituição de 1988 não ter inovado na base legal sobre o aborto - já que a sua prática continuava a ter um caráter punitivo para as mulheres, exceto nos casos decorrentes de estupro e risco para a gestante, foi uma grande vitória que o texto da Constituição não tivesse a expressão "garantir a vida desde a concepção", uma vez que isso permitia que o Brasil fosse signatário de acordos e tratados internacionais sem a interferência de pensamentos e ações conservadoras possíveis caso a afirmativa constasse no texto da Constituinte.
\end{abstract}

Ainda na luta pela transformação da condição da mulher, o movimento feminista conseguiu instituir a presença do Estado brasileiro em ciclos de debates internacionais que abordam a questão dos direitos humanos, como na Constituição de 1988 do país, que impõe

[...] a ratificação de documentos internacionais do qual o Brasil fosse signatário, o movimento feminista passou a se organizar e pressionar o Estado brasileiro para assinar os documentos que garantem a ampliação e o reconhecimento dos direitos das mulheres. (MAYORGA; MAGALHÃES, 2008, p. 159).

A luta feminista nacionalmente, embora não conseguindo retirar o aborto da secção penal, alcançou efetividade de demandas relacionada aos direitos sexuais e reprodutivos, no tocante sobre o aborto, por meio do Estado, elaboradas a partir do que foi posto na constituinte: a criação de mecanismos e instituições que atendam casos de aborto, pela rede públi- ca, já permitidos por lei; criação da norma técnica de atenção às mulheres em situação de abortamento. Ademais, a legalização do aborto nos casos permitidos por lei e pela jurisprudência (aborto de fetos anencéfalos também é pauta da luta feminista). Essas e demais conquistas do movimento feminista pela defesa e materialização dos direitos das mulheres sempre foi pleiteada com os grupos conservadores presentes no Parlamento e na sociedade civil.

Destacamos ainda a organização de conferências das mulheres: A Conferência de Mulheres Brasileiras (2002) e as Conferência Nacional de Políticas para as Mulheres (CNPM) (2004/2007/2011/2016) foram marcos para o debate sobre o aborto no território nacional mesmo com a contraofensa dos grupos conservadores e fundamentalistas religiosos que põe desafios para a materialização dos planos e projetos desenvolvidos nestas conferências.

A exemplo da organização estratégica e mobilização dos movimentos feministas temos os atos Legalizar o aborto pela vida das mulheres! que ocorreu no Rio de Janeiro no ano de 2014 e Chega de Mortes de Mulheres! Congresso tire a mão do nosso corpo em São Paulo em 2016; a IV Ação Internacional das Marcha Mundial das Mulheres no Rio Grande do Sul, em que debateu sobre o aborto com cerca de 500 mulheres do Brasil, Argentina e Uruguai; a Virada Feminista (2016) organizada a partir da Marcha Mundial das Mulheres (MMM) e da Sempreviva Organização Feminista (SOF) que promoveu diversas atividades e ações culturais em São Paulo além de uma mobilização virtual com a hashtag \#PrecisamosFalarSobreAborto com 24 horas de debate ao vivo sobre o aborto.

Assim, o feminismo é necessário: constitui como uma ação política que articula a questão da mulher com as expressões da questão social a fim de denunciar a opressão de gênero e alcançar a emancipação feminina. Parte-se, então, da experiência comum das mulheres para revelar e refutar, em conjunto com arcabouço teórico, a ideologia patriarcal (OLIVEIRA, 2013; CISNE, 2014). Desse modo, [...] cabe ao movimento feminista construir uma 'contra ideologia', que desconstrua a naturalização da delimitação dos pa- 
péis e dos lugares onde homens e mulheres são convidados a permanecer pela divisão sexual do trabalho (OLIVEIRA, 2013, p. 5).

Destarte, o feminismo materialista põe em evidência a base material da opressão feminina, contribuindo para a desmistificação da condição social das mulheres, percebendo-a dentro de uma totalidade concreta. Para além disso, subsidia esclarecer e expor o capitalismo e suas multifacetadas, contestando a propriedade, apropriação e a expropriação, apontando que a transformações devem ser de cunho estrutural para que mulheres e homens atinjam a emancipação, passando a se reconhecerem enquanto humanos genéricos (BENOIT, 2000).

Portanto, a perspectiva classista ou marxista da luta feminista, a questão da legalização e descriminalização do aborto articulam o sistema patriarcal com o capitalismo, considerando estes como as bases estruturantes da negação dos direitos das mulheres a acesso ao procedimento de abortamento seguro e legal.

Dessa maneira, o aborto embora uma questão específica, possibilita a sua problematização da necessidade de não apenas desmistificar o patriarcado, mas também desvelar o capitalismo. A pauta, então, para o feminismo marxista constitui-se além de um direito importante para o exercício da cidadania e autonomia feminina, um elemento que viabiliza, por meio de investigação, aportes para apreender as determinações produtivas nas relações sociais.

\section{CONSIDERACÕES FINAIS}

Ante as questões abordadas ao longo desse artigo, destacamos as expressões do conservadorismo em um momento de recrudescimento como componente do complexo processo de luta entre as classes, rebatendo na vida das mulheres, com recorte especial das que recorrem à prática do aborto, como expressão de valores capitalistas, patriarcais e de vinculação religiosa.

No âmbito das classes, as consequências de uma prática demarcada como ilegal e determinada pelas relações mercadológicas, aponta para um quadro de criminalização, negação de direitos e mortalidade, principalmente para as mulheres pobres, em sua maioria negra e que não consomem saúde, além de não ter acesso à saúde pública.

Logo, a luta feminista classista de teoria marxista, o feminismo chama a atenção para a seguinte problemática: não é só pela transformação da sociedade de classe para uma socialista que automaticamente a opressão de gênero irá desaparecer. Portanto, a direção da luta revolucionária não deve ser apenas pelo fim das classes: deve apreender que a classe é constituída por sujeitos plurais, e, por isso, a luta deve abarcar a necessidade de extinguir todas as formas de desigualdades, incorporando a necessidade de emancipação das mulheres, o exercício de autonomia sobre os seus corpos por elas mesmas e a superação do Estado burguês como mediador da contradição das classes e materializador do patriarcado.

\section{REFERÊNCIAS}

AGUIRRE, Luis Pérez. Aspectos religiosos do aborto induzido. Cadernos católicas pelo direito de decidir, Tradução de Adail Sobral, n.5. São Paulo: Católicas Pelo Direito de Decidir, 2006.

BENOIT, Lelita Oliveira. Feminismo, gênero e revolução. Crítica Marxista, São Paulo: Boitempo, v.1, n.11, p.76-78, 2000.

BÍBLIA Sagrada. São Paulo: Paulina, 2011. 1504 p.

\section{BOEHM, Camila. Ato em São Paulo pede a}

legalização do aborto. Empresa Brasil de Comunicação, 2016. Disponível em: <http:// agenciabrasil.ebc.com.br/geral/noticia/2016-12/ manifestantes-protestam-na-avenida-paulista-pelodireito-ao-aborto>. Acesso em: 8 mar. 2017.

BRASIL. Projeto de Lei $\mathbf{n}^{\circ} \mathbf{1 5 4 5}$, de 2011. Inclui art. 128-A no Decreto-Lei no 2.848 , de 07 de dezembro de 1940. Disponível em: <http://www.camara.gov.br/ 
proposicoesWeb/prop_mostrarintegra?codteor=88499 2\&filename $=P L+1545 / 2011$ > . Acesso em: 1 out. 2016.

\section{BRASIL. Constituição da República Federativa do \\ Brasil. Brasília: Senado Federal, 1988.}

BRASIL. Projeto de Lei $\mathbf{n}^{\mathbf{0}} \mathbf{4 3 6 0}$, de 2004. Acrescenta inciso ao artigo 128 do Decreto-Lei n 2.848 , de 7 de dezembro de 1940. Disponível em: <http://www. camara.gov.br/proposicoesWeb/prop_mostrarintegr a;jsessionid=9C5471FD2DE6BF2C8A4F5BE8660F5 E9A.proposicoesWeb2?codteor $=249178 \&$ filename $=$ PL+4360/2004>. Acesso em: 2 out. 2016.

BRASIL. Projeto de Lei $\mathbf{n}^{\mathbf{0}} \mathbf{7 4 4 3 / 2 0 0 6}$. Dispõe sobre a inclusão do tipo penal de aborto como modalidade de crime hediondo. Disponível em: <http://www.camara. gov.br/proposicoesWeb/prop_mostrarintegra;jsessi onid=557812BDC062DFCEAF0D3B659C423767. pro posicoesWebExterno1?codteor $=416204 \&$ filename $=$ PL+7443/2006>. Acesso em: 1 out. 2016.

BRASIL. Projeto de Lei $\mathbf{n}^{\mathbf{0}} \mathbf{4 7 8 / 2 0 0 7}$. Dispõe sobre o Estatuto do Nascituro e dá outras providências. Disponível em: <http://www.camara.gov.br/ proposicoesWeb/prop_mostrarintegra?codteor $=44358$ 4\&filename=PL+478/2007 >. Acesso em: 3 out. 2016.

\section{BRASIL. Proposta de Emenda à Constituição n⿳0}

164, de 2012. Dá nova redação ao caput do art. $5^{\circ} \mathrm{da}$ Constituição Federal. Disponível em: <http://www. camara.gov.br/proposicoesWeb/prop_mostrarinte gra?codteor=987629\&filename=PEC+164/2012>. Acesso em: 2 out. 2016.

BRASIL. Projeto de Lei n⿳0 5069, de 2013. Acrescenta 0 art. 127-A ao Decreto-Lei no 2.848, de 7 de dezembro de 1940 - Código Penal. Disponível em: <http://www.camara.gov.br/proposicoesWeb/ prop_mostrarintegra?codteor=1061163\&filename= $P L+5069 / 2013>$. Acesso em: 1 out. 2016.
BRASIL. Projeto de Lei n o 5.617, de 2016. Institui o dia nacional de conscientização antiaborto. Disponível: <http://www.camara.gov.br/sileg/ integras/1470523.pdf>. Acesso em: 1 nov. 2016.

\section{CISNE, Mirla. Feminismo e consciência de classe no}

Brasil. São Paulo: Cortez, 2014.

DINIZ, Debora; MEDEIROS, Marcelo. Aborto no Brasil: uma pesquisa domiciliar com técnica de urna. Ciência \& Saúde Coletiva, v.15 (Supl. 1), p.959-966, 2010.

Disponível em: <http://www.apublica.org/wp-content/ uploads/2013/09/PNA.pdf>. Acesso em: 23 nov. 2016.

\section{MARTINS, Fillipe Perantoni. Teleologia e}

causalidade na práxis política: momento ideal do partido frente às manifestações de junho de 2013. 2015. 144f. Dissertação (Mestrado em Serviço Social) - Universidade Federal de Juiz de Fora, Juiz de Fora, 2015. Disponível em: <http://www.ufjf. br/ppgservicosocial/files/2015/03/fillipe.pdf $>$. Acesso em: 25 dez. 2016.

MARX, K.; ENGELS, F. A ideologia alemã. Tradução de Álvaro Pina. São Paulo: Expressão Popular, 2009.

MAYORGA, Claudia; MAGALHÃES, Manuela de Sousa. Feminismo e as lutas pelo aborto legal ou por que a autonomia das mulheres incomoda tanto? In: MAIA, Mônica Bara (Org.). Direito de decidir: múltiplos olhares sobre o aborto. Belo Horizonte: Autêntica, 2008.

MONTAÑO, Carlos; DURIGUETTO, Maria Lúcia. Estado, classe e movimento social. 3.ed. São Paulo: Cortez, 2011.

NAME, Paula Carmo. Dos princípios que fundamentam a relação estado e religião. Pontoe-Vírgula. Revista de Ciências Sociais, São Paulo, n.4, p.71-85, 2008. Disponível em: <http:// revistas.pucsp.br/index.php/pontoevirgula/article/ viewFile/14160/10405>. Acesso em: 25 dez. 2016. 
OLIVEIRA, L.S. Movimento Feminista: sujeito político e coletivo central na luta das mulheres. In: Seminário Internacional Fazendo Gênero: desafios atuais do feminismo, 2013. Anais Fazendo Gênero 10. Florianópolis: Fazendo Gênero, v.1, p.1-10, 2013. Disponível em: <http:// www.fg2013.wwc2017.eventos.dype.com.br/ resources/anais/20/1373320687 ARQUIVO_ artigofazendogenero2013.pdf>.

Acesso em: 2 jan. 2017.
SILVA, Adriana Brito da et al. A extrema-direita na atualidade. Serv. Soc. Soc., São Paulo, n.119, p.407-445, jul-set. 2014. Disponível em: <http:www.scielo.br/scielo. php?script=sci_arttextEpi=S0101-66282014000300002>. Acesso em: 25 dez. 2016.

TAROUCO, Gabriela da Silva; MADEIRA, Rafael Machado. Partidos, programas e o debate sobre esquerda e direita no Brasil. Revista de Sociologia e Política, v.21, n.45, p.149-165, mar. 2013. Disponível em: <http://www.scielo.br/pdf/rsocp/v21n45/ a11v21n45.pdf >. Acesso em: 25 dez. 2016. 
